\title{
Diagnosis and treatment of coagulopathy secondary to single fetal demise in twin pregnancy
}

\author{
Jennia Michaeli ${ }^{1, *}$, Ella Kitroser ${ }^{2}$, Alexander Ioscovich ${ }^{3}$, Arnon Samueloff ${ }^{4}$, Hen Y. Sela ${ }^{5}$ \\ ${ }^{1,2}$ Consultant, ${ }^{3}$ Associate Professor, ${ }^{4}$ Professor, ${ }^{5}$ Senior Lecturer, $, 1,2,4,5$ Dept. of Obstetrics and Gynecology, ${ }^{3}$ Dept. of \\ Anesthesiology, Shaare Zedek Medical Center Affiliated with the Hebrew University, Hadassah School of Medicine, Jerusalem, \\ Israel.
}

\section{*Corresponding Author: Jennia Michaeli}

Email: jennia1807@gmail.com

Accepted: $2^{\text {nd }}$ November, 2018

Received: $14^{\text {th }}$ November, 2018

\begin{abstract}
Introduction: Disseminated intravascular coagulation following single fetal demise in a twin pregnancy is a rare event. As such, the diagnosis and management of such cases are complicated and require the assistance of various laboratory tests.

Case: 26 years old patient, carrying dichorionic diamniotic twin pregnancy was complicated by single fetal demise at $21+6$ weeks and preterm premature rupture of membranes (PPROM) at $24+5$ weeks. Pregnancy was managed conservatively until $30+4$ weeks gestation when abnormal laboratory tests including dysfibrinogenemia and pathological thromboelastogram (TEG) indicated the development of disseminated intravascular coagulopathy (DIC) while the patient remained asymptomatic. A multidisciplinary team decided on prompt delivery by cesarean section. Cesarean delivery (CD) was uneventful, yet post-operative course was complicated by worsening laboratory tests and post-partum hemorrhage that were treated by uterotonics and blood products resulting in clinical and laboratory normalization.

Conclusion: DIC following single fetal demise in a twin pregnancy is rare. A new laboratory test, TEG, may aid in diagnosis and management of DIC.
\end{abstract}

Keywords: Twins, Disseminated intravascular coagulation (DIC), Intrauterine fetal demise (IUFD), Thromboelastogram (TEG), Coagulopathy.

\section{Introduction}

Intrauterine fetal demise (IUFD) complicated by DIC is a rare but known complication of singleton pregnancies and should be screened for. ${ }^{1}$ Coagulation abnormalities are due to the gradual release of tissue factor from the placenta into the maternal circulation. ${ }^{1}$ Unlike singleton pregnancies, twin pregnancies with single IUFD (spontaneous or via selective termination) are rarely complicated by DIC, and our search of the literature revealed that only four cases are published. ${ }^{2-5}$

Lately, an increasing amount of data shows that the diagnosis of the DIC severity and the risk of bleeding assessed by measurement of fibrinogen levels and not by levels of PT/PTT. ${ }^{6}$ In addition, the use of bedside methods for rapid interpretation of the coagulation state of pregnant patients, such as Thromboelastography and Thromboelastometry, is becoming more common. The utilization of these methods is strongly recommended by the various Obstetric Anesthesia organizations. ${ }^{7} \mathrm{We}$ hereby present a rare case of twin pregnancy complicated by single IUFD and latter complicated by DIC. Coagulopathy was diagnosed and managed with the aid of TEG.

\section{Case}

A 26-year-old woman gravida 4 para 3 carrying a dichorionic diamniotic twin pregnancy was referred to our center at $21+6$ weeks due to hydrops of both twins. On our scan, hydrops fetalis of both twins with middle cerebral artery peak systolic velocity (MCA PSV) flow correlating with severe fetal anemia was diagnosed, the rest of the fetal anatomic scan was normal. Later the diagnosis of Parvovirus infection was confirmed via maternal serology, anti-Parvovirus $\operatorname{IgG}$ and $\operatorname{IgM}$ were positive, and PCR from amniocentesis of both fetuses was positive for Parvovirus. Fetal anemia was treated by an intrauterine blood transfusion at a different fetal therapy center. Twin A was treated by an intracardiac transfusion that unfortunately resulted in an IUFD. Twin B was treated by a successful intrahepatic vein transfusion that resulted in quick improvement of the hydrops and anemia as presented in improved MCAPSV values and resolution of hydrops on repeated fetal scans. The woman suffered from mirror syndrome during the period of fetal hydrops but quickly recovered on the resolution of fetal anemia.

The patient presented at $24+5$ weeks with preterm premature rupture of the membranes (PPROM) of the demised twin A. She was treated with a 24-hour course of betamethasone and a one week course of ampicillin and roxithromycin (standard protocol for PPROM in our department). Routine sonography and laboratory tests were performed three times weekly, and a non-stress test (NST) for twin B was performed daily. Twin B suffered from intrauterine growth restriction most likely due to the Parvovirus infection with estimated fetal weight (EFW) below the $3^{\text {rd }}$ percentile at presentation. Fetal weight gradually increased to reach the $8^{\text {th }}$ percentile at the time of delivery; no sign of recurrent fetal anemia was noted during hospitalization. The course of her stay 
was unremarkable with no signs of chorioamnionitis or excessive bleeding.

At 30 weeks and 5 days gestation, routine blood tests revealed dysfibrinogenemia: $105 \mathrm{mg} / \mathrm{dL}$ measured by PT-derived method (HemosIL RecombiPlasTin 2G) and $85 \mathrm{mg} / \mathrm{dL}$ measured by Clauss assay. Normal fibrinogen levels in the third trimester of pregnancy are $373-619 \mathrm{mg} / \mathrm{dL} .{ }^{8}$ Other coagulation functions (PT, PTT, and INR) were normal. Platelet count was within the low normal range, with the nadir of 150,000, and remained stable. The patient was asymptomatic, had normal vital signs, and no vaginal or other bleeding. The skin was normal with no petechiae or hematomas. Further blood tests were indicative of DIC. Fibrinogen levels were confirmed to be low $114 \mathrm{mg} / \mathrm{dL}$ (PT-derived method), D-Dimer was extremely high 35,088 ng/mL, normal D-Dimer levels in the third trimester of pregnancy are $130-1700 \mathrm{ng} / \mathrm{mL} .^{8}$ Thromboelastogram (TEG) was abnormal with a decrease in the maximum amplitude (MA) down to $37 \mathrm{~mm}$ (normal range $50-70$ ). A reduction in $\mathrm{G}$ (as a sign of fibrinolysis) alongside a coagulation index (CI) increase up to 3.8 (normal range $-3-3$ ) were also observed (Fig. 1).

Considering the above mentioned abnormal laboratory findings and consulting an expert opinion of a multidisciplinary team including a maternal-fetal medicine expert, hematologist, and anesthesiologist we established the diagnosis of consumption coagulopathy despite the fact that the patient was asymptomatic. Taking into consideration the long latency period of pregnancy after single IUFD and PPROM in combination with current gestational age, we decided upon prompt delivery of the fetus due to the unpredictable nature of the condition and possibly fatal consequences for both mother and fetus. Since the live twin B was the in breech presentation along with the unknown timeline and severity of maternal coagulopathy, we decided to perform a cesarean section after completion of rescue dose of betamethasone. Prior to surgery, the patient was treated with ten units of cryoprecipitate, but dysfibrinogenemia did not fully recover (fibrinogen $186 \mathrm{mg} / \mathrm{dL}$ ). General anesthesia was chosen due to signs of coagulopathy to prevent the minor risk of epidural or spinal bleeding as a result of regional anesthesia. The fetus was delivered via a low segment cesarean section.

The course of the surgery was normal with no excessive bleeding. Shortly (about $15 \mathrm{~min}$.) after surgery repeat laboratory tests worsened with lower fibrinogen levels $(114 \mathrm{mg} / \mathrm{dL})$ and an abnormal TEG result. The patient developed an early post-partum hemorrhage with vaginal bleeding estimated at $1000 \mathrm{~mL}$. She was treated with fresh frozen plasma and packed cells for her coagulation disorder combined with uterotonics (oxytocin, methylergometrine, and misoprostol). The following laboratory tests and post-operative course were normal. The baby was released from the Neonatal intensive care unit at the age of 2.5 months with no prematurity complications, to date is a healthy girl.

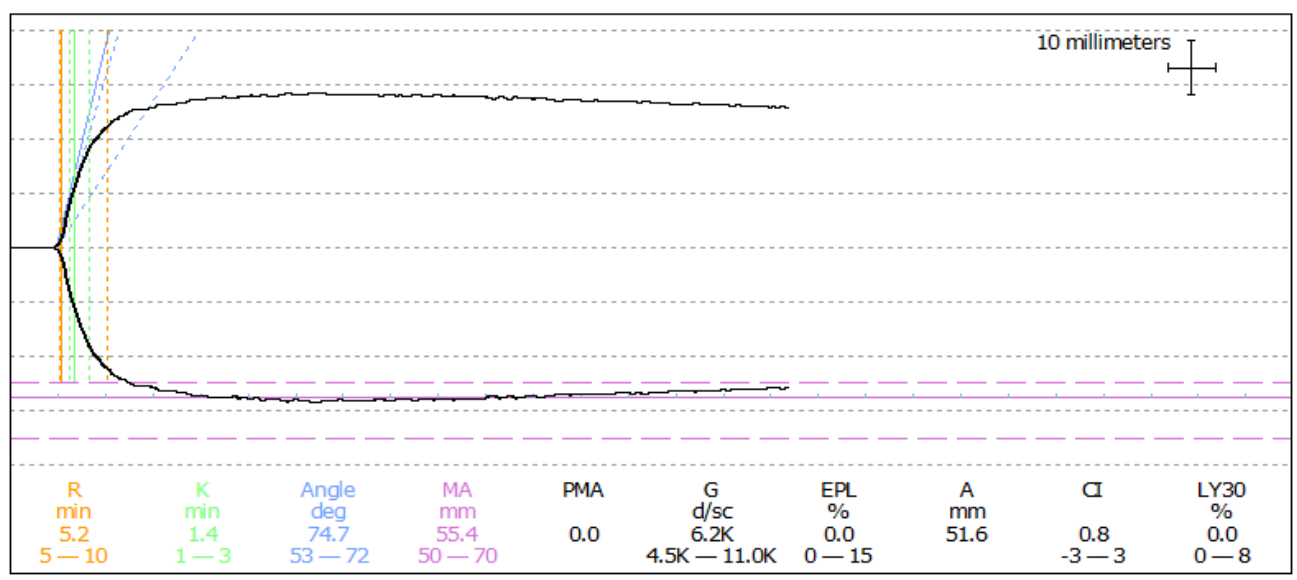

Fig. 1: Patient's initial thromboelastogram, indicating DIC

\section{Discussion}

DIC arises from the release of tissue factor. In obstetrics, the origin may be trophoblastic tissue or amniotic fluid and usually caused by endothelial activation that leads to diffuse activation of the coagulation cascade. Activated coagulation and fibrinolysis evolve into a consumptive coagulopathy when coagulation factors and platelets are depleted. It is considered a frequent cause of maternal morbidity and mortality and is associated with up to $25 \%$ of maternal deaths. ${ }^{9}$
Proper treatment of this rare and potentially dangerous complication relays on early recognition and diagnosis. Frequently, the diagnosis of DIC is challenging and delayed since no single clinical or laboratory test is specific to this condition. Furthermore, the regular coagulation function tests are not well defined during pregnancy, and their normal levels are known to be different from the non-pregnant state. For example, normal fibrinogen levels for the third trimester are $373-619 \mathrm{mg} / \mathrm{dL}$ and normal D-Dimer levels in the third trimester are $130-1700 \mathrm{ng} / \mathrm{mL}^{8}$ 
Twin pregnancy accounts for $3.5 \%$ of all births in the USA. Single fetal demise is estimated to occur in $2.4 \%$ of all twin pregnancies. ${ }^{10}$ Approximately $1 \%$ of twin fetuses may be candidates for selective reduction due to discordancy for chromosomal or structural anomalies. ${ }^{11}$

The rare case presented above demonstrates a consumptive coagulopathy due to DIC following single fetal demise in a twin pregnancy and may be associated with a bleeding tendency. The data on this topic is quite scarce, and our search of the literature resulted in only four case reports of DIC in twin pregnancies that were complicated by single fetal demise. Our case resulted in a live newborn and a healthy mother. It is possible that the favorable outcome was partly accounted for the quick diagnosis using various laboratory tests including TEG, to confirm the diagnosis of DIC in an asymptomatic patient.

DIC is yet another example of the utilization of TEG in diagnosis and treatment of various obstetrics indications such as Thrombocytopenia, ${ }^{12}$ Coagulation Factor deficiency, ${ }^{13}$ and Amniotic Fluid Embolism. ${ }^{14}$

We believe that the trend of using TEG in obstetrics will continue. Use of TEG should be promoted to improve care management further and increase the quality of patient outcomes.

Funding: No funding or other financial support was received for this work.

Conflict of interest: All authors declare they have no conflict of interest.

\section{References}

1. Shek NWM, Hillman SC, Kilby MD. Single-twin demise: Pregnancy outcome. Best Pract Res Clin Obstet Gynaecol. 2014.

2. Eddib A, Rodgers B, Lawler J, Yeh J. Monochorionic pseudomonoamniotic twin pregnancy with fetal demise of one twin and development of maternal consumptive coagulopathy. Ultrasound Obstet Gynecol. 2006;28(5):736-7. Available from: http://doi.wiley.com/10.1002/uog.3817

3. Romero R, Duffy TP, Berkowitz RL, Chang E, Hobbins JC. Prolongation of a preterm pregnancy complicated by death of a single twin in utero and disseminated intravascular coagulation. Effects of treatment with heparin. N Engl J Med. 1984;310(12):772-4. Available from: http://www.nejm.org/doi/abs/10.1056/NEJM1984032231 01207

4. Skelly H, Marivate M, Norman R, Kenoyer G, Martin R. Consumptive coagulopathy following fetal death in a triplet pregnancy. Am J Obstet Gynecol. 1982;142(5):595-6. Available from: http://www.ncbi.nlm.nih.gov/pubmed/7199261

5. Novak CM, Patel S V, Baschat AA, Hickey KW, Petersen SM. Maternal coagulopathy after umbilical cord occlusion for twin reversed arterial perfusion sequence. Obstet Gynecol. 2013;122(2 Pt 2):498-500. Available from: http://content.wkhealth.com/linkback/openurl?sid=WKPT
LP:landingpage \&an=00006250-201308002-00025

6. Cortet M, Deneux-Tharaux C, Dupont C, Colin C, Rudigoz R-C, Bouvier-Colle M-H, et al. Association between fibrinogen level and severity of postpartum haemorrhage: secondary analysis of a prospective trial. $\mathrm{Br}$ J Anaesth. 2012;108(6):984-9. Available from: https://academic.oup.com/bja/articlelookup/doi/10.1093/bja/aes096

7. Association of Anaesthetists of Great Britain \& Ireland. OAA / AAGBI Guidelines for Obstetric Anaesthetic Services 2013. OAA / AAGBI Guidel. 2013.

8. Abbassi-Ghanavati M, Greer LG, Cunningham FG. Pregnancy and Laboratory Studies. Obstet Gynecol. 2009;114(6):1326-31. Available from: http://www.ncbi.nlm.nih.gov/pubmed/19935037

9. Cunningham FG, Nelson DB. Disseminated Intravascular Coagulation Syndromes in Obstetrics. Obstet Gynecol. 2015;126(5):999-1011. Available from: http://www.ncbi.nlm.nih.gov/pubmed/26444122

10. Pharoah PO, Adi Y. Consequences of in-utero death in a twin pregnancy. Lancet. (London, England). 2000;355(9215):1597-602. Available from: http://www.ncbi.nlm.nih.gov/pubmed/10821363

11. Egan E, Reidy K, O’Brien L, Erwin R, Umstad M. The Outcome of Twin Pregnancies Discordant for Trisomy 21. Twin Res Hum Genet. 2014;17(01):38-44. Available from: http://www.ncbi.nlm.nih.gov/pubmed/24229497

12. Huang J, McKenna N, Babins N. Utility of thromboelastography during neuraxial blockade in the parturient with thrombocytopenia. AANA J. 2014;82(2):127-30. Available from: http://www.ncbi.nlm.nih.gov/pubmed/24902455

13. Othman M, Falcón B, Kadir R. Global Hemostasis in Pregnancy: Are We Using Thromboelastography to Its Full Potential? Semin Thromb Hemost. 2010;36(07):73846. Available from: http://www.ncbi.nlm.nih.gov/pubmed/20978994

14. Drukker L, Sela HY, Ioscovich A, Samueloff A, GrisaruGranovsky S. Amniotic Fluid Embolism: A Rare Complication of Second-Trimester Amniocentesis. Fetal Diagn Ther. 2017;42(1):77-80. Available from: http://www.ncbi.nlm.nih.gov/pubmed/27287307

How to cite this article: Michaeli J, Kitroser E, Ioscovich A, Samueloff A, Sela H. Y. Diagnosis and treatment of coagulopathy secondary to single fetal demise in twin pregnancy. Indian J Obstet Gynecol Res. 2018;5(4):573-575. 